URBAN, Renan Lucas Dutra. Conflitos normativos e ponderação no novo código de processo civil: problemas teóricos, conceituais e metodológicos. Revista Eletrônica Direito e Política, Programa de Pós-Graduação Stricto Sensu em Ciência Jurídica da UNIVALI, Itajaí, v.14, n.1, $1^{\circ}$ quadrimestre de 2019. Disponível em: www.univali.br/direitoepolitica - ISSN 1980-7791

\title{
CONFLITOS NORMATIVOS E PONDERAÇÃO NO NOVO CÓDIGO DE PROCESSO CIVIL: PROBLEMAS TEÓRICOS, CONCEITUAIS E METODOLÓGICOS
}

\author{
NORMATIVE CONFLICTS AND BALANCING IN THE NEW CIVIL PROCEDURE CODE: \\ THEORETICAL, CONCEPTUAL, AND METHODOLOGICAL PROBLEMS
}

Renan Lucas Dutra Urban ${ }^{1}$

\begin{abstract}
RESUMO
A ponderação é objeto de críticas as mais diversas no âmbito da teoria do Direito. Por um lado, há a objeção que questiona a objetividade e a racionalidade dessa forma de aplicação do Direito. Por outro, há a crítica relacionada à falta de rigor na utilização dessa categoria e de outros conceitos da teoria dos princípios de Robert Alexy. Este trabalho visa a analisar alguns problemas de ordem teórica, conceitual e metodológica que subjazem ao artigo 489, parágrafo segundo, do novo Código de Processo Civil, o qual prevê a possibilidade de se aplicar a ponderação para a solução dos conflitos normativos. Com base especialmente na dimensão analítica da abordagem dogmática, procura-se enfatizar, aqui, os perigos de uma prática jurídica confusa, isto é, que se vale da ponderação - e de outras ferramentas argumentativas - sem se atentar para seus pressupostos e implicações.
\end{abstract}

PALAVRAS-ChAVE: novo Código de Processo Civil; conflitos normativos; Robert Alexy; ponderação; proporcionalidade.

\section{ABSTRACT}

Balancing is subject of criticism in the context of legal theory. On the one hand, there is the objection that questions the objectivity and rationality of this form of applying norms. On the other, there is criticism related to the lack of rigor in the use of this category and of other concepts of the theory developed by Robert Alexy. This paper aims to study some theoretical, conceptual and methodological

\footnotetext{
1 Mestre em Direito pela Universidade Estadual Paulista "Júlio de Mesquita Filho", Faculdade de Ciências Humanas e Sociais (UNESP, Campus de Franca), graduado em Direito pela mesma instituição. Franca - São Paulo - Brasil. Membro do grupo de pesquisa CNPq "Núcleo de Estudos Avançados em Direito Processual Civil Brasileiro e Comparado" (NUPAD/UNESP). E-mail: renanurban@hotmail.com.
} 
URBAN, Renan Lucas Dutra. Conflitos normativos e ponderação no novo código de processo civil: problemas teóricos, conceituais e metodológicos. Revista Eletrônica Direito e Política, Programa de Pós-Graduação Stricto Sensu em Ciência Jurídica da UNIVALI, Itajaí, v.14, n.1, $1^{\circ}$ quadrimestre de 2019. Disponível em: www.univali.br/direitoepolitica - ISSN 1980-7791

problems implied in article 489, second paragraph, of the new Code of Civil Procedure, which establishes the application of the balancing for the resolution of conflicts between legal norms. Focusing especially on the analytical dimension of the dogmatic approach, this paper aims to emphasize the dangers of a confusing legal practice, which uses balancing - and other argumentative tools disregarding its assumptions and implications.

KEYWORDS: new Civil Procedure Code, normative conflicts, Robert Alexy, defeasibility, balancing, proportionality

\section{INTRODUÇÃO}

O novo Código de Processo Civil, ao disciplinar a fundamentação das decisões judiciais, dispõe, em seu artigo 489, parágrafo segundo, que

No caso de colisão entre normas, o juiz deve justificar o objeto e os critérios gerais da ponderação efetuada, enunciando as razões que autorizam a interferência na norma afastada e as premissas fáticas que fundamentam a conclusão. ${ }^{2}$

Trata-se, sem dúvida, de uma novidade, na medida em que consagra uma forma específica de aplicação e de interpretação do Direito, associada sobretudo à chamada "teoria dos princípios", nos moldes como elaborada por Robert Alexy e difundida por seus adeptos: a ponderação.

A ponderação, ou sopesamento, é objeto de críticas as mais diversas no âmbito da teoria do Direito. Este trabalho explora duas vertentes. A primeira aponta para o caráter discricionário das decisões ponderativas. Ela é endereçada especialmente pelos adversários da teoria de Alexy, que manifestam seu ceticismo quanto à capacidade da ponderação para fundamentar decisões racionais e objetivas. A outra vertente não contesta as premissas centrais da teoria dos princípios e, portanto, não necessariamente rejeita a ponderação como forma de aplicação do Direito. Reprova, porém, os casuísmos e os voluntarismos judiciais, decorrentes da falta de rigor conceitual e metodológico na utilização dessa categoria.

\footnotetext{
2 BRASIL. Lei n. 13.105 de 16 de março de 2015. Código de Processo Civil. Diário Oficial da União. Poder Executivo, Brasília, DF, 17/03/2015, p. 1. Disponível em: <www.planalto.gov.br/ccivil_03/_Ato2015-2018/2015/Lei/L13105.htm>. Acesso em: 16 de setembro de 2018.
} 
URBAN, Renan Lucas Dutra. Conflitos normativos e ponderação no novo código de processo civil: problemas teóricos, conceituais e metodológicos. Revista Eletrônica Direito e Política, Programa de Pós-Graduação Stricto Sensu em Ciência Jurídica da UNIVALI, Itajaí, v.14, n.1, $1^{0}$ quadrimestre de 2019. Disponível em: www.univali.br/direitoepolitica - ISSN 1980-7791

Essas objeções compõem o objeto deste trabalho. Mais do que avaliar, em profundidade, os argumentos relacionados a cada uma delas, o que interessa, para os fins deste texto, é, em primeiro lugar, apresentar as controvérsias de ordem teórico-filosófica que gravitam em torno da ponderação (seção 1); em segundo lugar, ressaltar a inadequação de sua utilização como forma de solução de todo e qualquer conflito entre normas (seção 2.1); e, por fim, salientar os deveres de fundamentação que decorrem da própria realização do sopesamento (seção 2.2).

Este trabalho, portanto, visa a analisar alguns problemas de ordem teórica, conceitual e metodológica que subjazem ao artigo 489, parágrafo segundo, do novo Código de Processo Civil. O estudo desenvolvido se justifica, assim, não apenas por sua importância teórica, consistente em aclarar conceitos da teoria princípios de Robert Alexy - marco teórico do trabalho -, mas também por sua importância prática, dadas as consequências nocivas, sobretudo para a segurança jurídica e para a eficiência decisória, que podem decorrer de abusos na aplicação do novo dispositivo normativo. Com base especialmente na dimensão analítica da abordagem dogmática, ${ }^{3}$ procura-se enfatizar, aqui, os perigos de uma prática jurídica confusa, isto é, que se vale da ponderação - e de outras ferramentas argumentativas - sem se atentar para seus pressupostos e implicações. ${ }^{4}$

\footnotetext{
${ }^{3}$ A dimensão analítica da abordagem metodológica dogmática é importante para o exame dos conceitos e das relações existentes entre os objetos pesquisados. Neste trabalho, ela se revela, sobretudo, na Seção 2.1, na qual são estudados os principais aspectos que permitem diferenciar as regras dos princípios, e na Seção 2.2, na qual são analisados os ônus argumentativos impostos pela aplicação da proporcionalidade e de sua terceira sub-regra, a ponderação. Cf., acerca das dimensões analítica, empírica e normativa da dogmática jurídica, SILVA, Virgílio Afonso da. A constitucionalização do direito: os direitos fundamentais nas relações entre particulares. São Paulo: Malheiros, 2008. p. 25-26; ALEXY, Robert. Teoria dos direitos fundamentais. Tradução de Virgílio Afonso da Silva. São Paulo: Malheiros, 2008. p. 32-38.

${ }^{4}$ A propósito do fascínio doutrinário pelos princípios jurídico-constitucionais - e dos abusos que, no âmbito jurisprudencial, a ele se associam -, cf. NEVES, Marcelo. Entre Hidra e Hércules: princípios e regras constitucionais como diferença paradoxal do sistema jurídico. São Paulo: Editora WMF Martins Fontes, 2013. p. 171-220.
} 
URBAN, Renan Lucas Dutra. Conflitos normativos e ponderação no novo código de processo civil: problemas teóricos, conceituais e metodológicos. Revista Eletrônica Direito e Política, Programa de Pós-Graduação Stricto Sensu em Ciência Jurídica da UNIVALI, Itajaí, v.14, n.1, $1^{\circ}$ quadrimestre de 2019. Disponível em: www.univali.br/direitoepolitica - ISSN 1980-7791

\section{IRRACIONALIDADE E SUBJETIVISMO: ALGUMAS CRÍTICAS À PONDERAÇÃO}

A teoria dos princípios, na forma como desenvolvida por Alexy, é objeto de críticas as mais diversas. Não é propósito deste trabalho fazer um panorama de todas elas. Enfatizam-se, aqui, apenas algumas das objeções que, no terreno da teoria do Direito e da argumentação jurídica, questionam a possibilidade de que, por meio da ponderação, se alcancem soluções racionais e objetivas para problemas envolvendo princípios.

As críticas à teoria dos princípios são especialmente intensas na Alemanha, país no qual se desenvolveu originariamente a chamada jurisprudência dos valores. Friedrich Müller, por exemplo, critica o Tribunal Constitucional alemão, o qual, a partir do caso Lüth, teria difundido o argumento de que, subjacente aos direitos fundamentais, há uma "ordem objetiva de valores" a conformar todos os ramos do Direito. Segundo Müller, a definição de uma "ordem hierárquica de valores", por meio de ponderações de bens ou princípios, não satisfaz a exigência do Estado de Direito de que as decisões judiciais sejam fundamentadas de modo objetivo e claro. Pelo contrário: as categorias dos "valores", do "sistema de valores" e da "valoração" ensejariam a produção de decisões vagas e discricionárias, já que, no fundo, concederiam ampla liberdade ao intérprete para motivá-las de acordo com suas preferências ideológicas. ${ }^{5}$

Jürgen Habermas também critica o recurso ao sopesamento como forma de aplicação dos princípios jurídicos. Segundo ele, as normas jurídicas, levadas a sério em sua dimensão deontológica, ou são válidas ou são inválidas, não podendo contradizer umas às outras. Habermas rejeita, assim, a definição dos princípios como mandamentos de otimização, na medida em que ela importaria a substituição do código binário típico do Direito - baseado na distinção válido/inválido - por uma racionalidade gradualista - que aceita a realização de sopesamentos entre valores orientados por um fim. Nesse sentido, ele rechaça especialmente o modelo teórico de Alexy, que, ao conferir às normas de direitos

${ }^{5}$ Cf. MÜLLER, Friedrich. Métodos de trabalho do direito constitucional. Tradução de Peter Naumann. 3. ed. Rio de Janeiro: Renovar, 2005. p. 16-20. 
URBAN, Renan Lucas Dutra. Conflitos normativos e ponderação no novo código de processo civil: problemas teóricos, conceituais e metodológicos. Revista Eletrônica Direito e Política, Programa de Pós-Graduação Stricto Sensu em Ciência Jurídica da UNIVALI, Itajaí, v.14, n.1, $1^{0}$ quadrimestre de 2019. Disponível em: www.univali.br/direitoepolitica - ISSN 1980-7791

fundamentais um sentido teleológico, teria equiparado a lógica de aplicação dos princípios jurídicos à dos valores.

Nos termos da concepção habermasiana, normas jurídicas válidas não podem disputar a primazia no caso concreto, pois isso macularia a consistência do sistema normativo. Além disso, segundo Habermas, não há nenhum critério racional capaz de ditar a prevalência de um valor sobre outro na solução de um problema. O sopesamento de valores ou princípios seria, nesse sentido, um procedimento irracional, um método do qual resultariam juízos irrefletidos e arbitrários. Porém, mais do que isso, ele seria também um procedimento perigoso, já que, por meio dele, direitos individuais poderiam ficar desprotegidos em face de interesses coletivos, sendo restringidos, caso a caso, em favor da realização destes. ${ }^{6}$

Também no âmbito da doutrina brasileira pode ser encontrada uma linha crítica ao recurso à teoria principialista de Alexy, e, especialmente, ao uso da ponderação como forma de interpretação e aplicação do Direito. Lenio Streck, por exemplo, critica a própria concepção teórica subjacente à categoria do sopesamento, apontando para o caráter discricionário das decisões que nela se baseiam. Conforme Streck, a teoria da argumentação jurídica de Alexy, ao sustentar que os "casos fáceis" podem ser resolvidos dedutivamente, isto é, com base na subsunção, estaria assentada num dos pressupostos da filosofia aristotélicotomista e da filosofia da consciência: o esquema sujeito-objeto. Assim, não obstante sua orientação pós-positivista, ela não teria conseguido superar o problema do solipsismo epistemológico, comum às diversas correntes positivistas. ${ }^{7}$ A ponderação, como forma de solução dos chamados "casos difíceis", reflete, afirma Streck, essa concepção metafísica da teoria argumentativa de Alexy, redundando numa delegação ao intérprete da resolução dos problemas jurídicos. ${ }^{8}$

${ }^{6}$ Cf. HABERMAS, Jürgen. Direito e democracia: entre facticidade e validade. Tradução de Flávio Beno Siebneichler. Rio de Janeiro: Tempo Brasileiro, 1997, v. 1. p. 315-322. Para uma análise crítica das objeções de Habermas à teoria dos princípios, cf. ALEXY, Robert. Constitutional rights, balancing and rationality. Ratio Juris, Oxford, v. 16, n. 2, jun. 2003. p. 131-140; SILVA, Virgílio Afonso da; MENDES, Conrado Hübner. Habermas e a jurisdição constitucional. In: NOBRE, Marcos; TERRA, Ricardo (orgs.). Direito e democracia: um guia de leitura de Habermas. São Paulo: Malheiros, 2008. p. 219-221.

7 STRECK, Lenio Luiz. Verdade e consenso. 3. ed. Rio de Janeiro: Lumen Juris, 2009. p. 466.

8 Nos termos de Streck, "(...) o calcanhar de Aquiles da ponderação - e, portanto, das diversas teorias argumentativas (e suas derivações) - reside no deslocamento da hierarquização ponderativa em 
URBAN, Renan Lucas Dutra. Conflitos normativos e ponderação no novo código de processo civil: problemas teóricos, conceituais e metodológicos. Revista Eletrônica Direito e Política, Programa de Pós-Graduação Stricto Sensu em Ciência Jurídica da UNIVALI, Itajaí, v.14, n.1, 10 quadrimestre de 2019. Disponível em: www.univali.br/direitoepolitica - ISSN 1980-7791

Ela seria, então, uma ferramenta arbitrária, que permite ao aplicador do Direito "assujeitar" o texto da norma para atribuindo-lhe sentidos arbitrariamente, conforme sua consciência (ou subjetividade). ${ }^{9}$

\section{CONCEITOS E EXIGÊnCIAS METOdOLÓGICAS DA TEORIA DOS PRINCÍPIOS}

\subsection{A Distinção Entre Regras e Princípios: As Diferentes Formas de Solução dos Conflitos Normativos}

O pressuposto da teoria principialista de Alexy é uma distinção forte entre regras e princípios. Regras e princípios, segundo esse autor, são normas jurídicas, na medida em que podem ser formulados por meio das expressões deônticas básicas do dever, da permissão e da proibição. ${ }^{10}$ Possuem, no entanto, distintas estruturas lógicas, o que permite considerá-las classes de normas diferentes.

A teoria de Alexy se contrapõe não apenas às teses que rejeitam possibilidade de se estabelecer uma distinção relevante entre as normas jurídicas, mas também às teorias que, baseadas em critérios materiais ou gradualistas - a generalidade e a fundamentalidade, por exemplo -, propõem uma distinção fraca ou débil para regras e princípios. ${ }^{11}$ Isso porque, nos termos de sua concepção, a diferença que existe entre essas normas não é de grau, mas de qualidade ou natureza. ${ }^{12}$

\footnotetext{
favor da subjetividade do intérprete, com o que a teoria da argumentação (para falar apenas desta), como sempre denunciou Arthur Kauffman, não escapa do paradigma da filosofia da consciência. Ou seja, independentemente das colorações assumidas pelas posturas que, de um modo ou de outro, deriva(ra)m da teoria da argumentação de Robert Alexy, o cerne da problemática está na continuidade da "delegação" em favor do sujeito da relação sujeito-objeto" (STRECK, Lenio Luiz. Verdade e consenso. 3. ed. Rio de Janeiro: Lumen Juris, 2009. p. 178-179).
}

9 Cf. STRECK, Lenio Luiz. Verdade e consenso. 3. ed. Rio de Janeiro: Lumen Juris, 2009. p. 172189.

10 ALEXY, Robert. Teoria dos direitos fundamentais. Tradução de Virgílio Afonso da Silva. São Paulo: Malheiros, 2008. p. 87.

${ }^{11}$ Cf. SILVA, Virgílio Afonso da. A constitucionalização do direito: os direitos fundamentais nas relações entre particulares. São Paulo: Malheiros, 2008. p. 29-32.

12 Dessa maneira, as teses que defendem uma distinção entre regras e princípios com base, por exemplo, na ideia - corrente na doutrina brasileira - de que princípios são "[...] mandamentos nucleares de um sistema, verdadeiro alicerce dele [...]" (BANDEIRA DE MELLO, Celso Antônio. Curso 
URBAN, Renan Lucas Dutra. Conflitos normativos e ponderação no novo código de processo civil: problemas teóricos, conceituais e metodológicos. Revista Eletrônica Direito e Política, Programa de Pós-Graduação Stricto Sensu em Ciência Jurídica da UNIVALI, Itajaí, v.14, n.1, ${ }^{\circ}$ quadrimestre de 2019. Disponível em: www.univali.br/direitoepolitica - ISSN 1980-7791

As regras, nos termos da teoria dos princípios de Alexy, são normas que exigem seja feito exatamente aquilo que elas prescrevem, nem mais, nem menos. ${ }^{13}$ Isso significa que as normas desse tipo, quando válidas e aplicáveis, devem ser aplicadas de maneira que seu conteúdo normativo - isto é, aquilo que elas estabelecem como juridicamente obrigatório, permitido ou proibido - seja realizado na sua totalidade. Definidas como mandamentos definitivos, as regras se contrapõem aos princípios ou mandamentos de otimização, ou seja, às normas que exigem a realização de algo na maior medida possível, de acordo com as condições fáticas e jurídicas do caso concreto. Os princípios, nos termos de Alexy, "[...] se caracterizam por poderem ser satisfeitos em graus variados e pelo fato de que a medida devida de sua satisfação não depende somente das possibilidades fáticas, mas também das possibilidades jurídicas."14

Alexy pensa a normatividade dos princípios segundo uma racionalidade gradualista, admitindo a possibilidade de que, numa colisão entre eles, um ceda em favor da satisfação do outro, sem que isso comprometa a validade da norma afastada. Ao definir princípios "como mandamentos de otimização", ele introduz um modo de pensar as normas jurídicas que destoa da racionalidade jurídica típica, baseada na díade válido/inválido. ${ }^{15}$ Essa metodologia tradicional continuaria pertinente para se trabalhar com regras, que se aplicariam por subsunção e cujos conflitos normativos se resolveriam no plano da validade, segundo a lógica "tudo ou nada". Ela não seria adequada, porém, para entender os princípios jurídicos,

\footnotetext{
de direito administrativo. 23. ed. São Paulo: Malheiros, 2007.p. 927), cuja violação é muito mais grave do que a das regras, não estão de acordo com a distinção estrutural entre regras e princípios proposta por Alexy. Como afirma Virgílio Afonso da Silva, "[...] uma norma é um princípio não por ser fundamental, mas por ter a estrutura de um mandamento de otimização. Por isso, um princípio pode ser um 'mandamento nuclear do sistema', mas pode também não o ser, já que uma norma é um princípio apenas em razão de sua estrutura normativa e não de sua fundamentalidade. O mesmo vale para as regras. Pode haver regras que sejam disposições fundamentais do sistema, mas isso é irrelevante para sua classificação." SILVA, Virgílio Afonso da. A constitucionalização do direito: os direitos fundamentais nas relações entre particulares. São Paulo: Malheiros, 2008. p. 36.
}

13 ALEXY, Robert. Teoria dos direitos fundamentais. Tradução de Virgílio Afonso da Silva. São Paulo: Malheiros, 2008. p. 91.

${ }^{14}$ ALEXY, Robert. Teoria dos direitos fundamentais. Tradução de Virgílio Afonso da Silva. São Paulo: Malheiros, 2008. p. 90.

15 Cf., no ponto, MENDES, Conrado Hübner. Direitos fundamentais, separação dos poderes e deliberação. 2008. 267 f. Tese (Doutorado em Ciência Política) - Faculdade de Filosofia, Letras e Ciências Humanas, Universidade de São Paulo, São Paulo, 2008. p. 32, nota de rodapé n. 59. 
URBAN, Renan Lucas Dutra. Conflitos normativos e ponderação no novo código de processo civil: problemas teóricos, conceituais e metodológicos. Revista Eletrônica Direito e Política, Programa de Pós-Graduação Stricto Sensu em Ciência Jurídica da UNIVALI, Itajaí, v.14, n.1, 10 quadrimestre de 2019. Disponível em: www.univali.br/direitoepolitica - ISSN 1980-7791

que se aplicariam por proporcionalidade e, por isso, seriam suscetíveis de ser precedidos por outros princípios no caso concreto, de acordo com as possibilidades fáticas e jurídicas.

De acordo com Alexy, a distinção entre regras e princípios se aclara sobretudo quando se analisa a forma de solução dos conflitos que ocorrem no interior de cada uma dessas classes de normas. A categoria dos conflitos normativos remete à ideia de que, num dado ordenamento jurídico, é possível que haja duas ou mais normas que, se isoladamente aplicadas, conduzem a juízos concretos de deverser contraditórios, dada a incompatibilidade parcial ou total das consequências jurídicas por elas previstas para o mesmo fato. ${ }^{16} \mathrm{O}$ gênero das normas jurídicas, como visto, comporta duas espécies: as regras e os princípios. Logo, é possível imaginar que haja conflitos entre regras, conflitos entre princípios e conflitos entre essas duas espécies normativas, ou seja, conflitos entre regras e princípios.

A solução de um conflito entre regras deve sempre levar em consideração o caráter definitivo delas. Assim, se duas regras preveem consequências jurídicas parcialmente incompatíveis entre si, deverá ser introduzida uma cláusula de exceção em uma delas, o que equivale a declará-la parcialmente inválida. Mas, se esse tipo de solução não for possível - ou seja: se a incompatibilidade entre elas não for do tipo parcial, mas total -, então uma delas deverá ser eliminada do ordenamento jurídico, por meio de uma declaração de invalidade jurídica total. Isso é assim porque, dentro de um mesmo sistema jurídico, não é possível que duas regras totalmente incompatíveis entre si sejam consideradas simultaneamente válidas. O conceito de validade jurídica, ressalta Alexy, não pode ser relativizado, graduado; se duas regras imputam consequências jurídicas diversas para a mesma situação fática, apenas uma delas - a que for declarada válida - poderá oferecer fundamento para a solução do problema. ${ }^{17}$

\footnotetext{
16 Acerca da definição de conflitos normativos, cf. ALEXY, Robert. Teoria dos direitos fundamentais. Tradução de Virgílio Afonso da Silva. São Paulo: Malheiros, 2008. p. 91-92; SILVA, Virgílio Afonso da. Direitos fundamentais: conteúdo essencial, restrições, eficácia. 2. ed. São Paulo: Malheiros, 2010. p. 47.

17 Cf. ALEXY, Robert. Teoria dos direitos fundamentais. Tradução de Virgílio Afonso da Silva. São Paulo: Malheiros, 2008. p. 92-93.
} 
URBAN, Renan Lucas Dutra. Conflitos normativos e ponderação no novo código de processo civil: problemas teóricos, conceituais e metodológicos. Revista Eletrônica Direito e Política, Programa de Pós-Graduação Stricto Sensu em Ciência Jurídica da UNIVALI, Itajaí, v.14, n.1, $1^{0}$ quadrimestre de 2019. Disponível em: www.univali.br/direitoepolitica - ISSN 1980-7791

A forma de solução dos conflitos entre princípios é diferente porque, ao contrário das regras, os princípios possuem uma "dimensão de peso", que condiciona sua realização definitiva à análise das condições fáticas e jurídicas do caso concreto. Um princípio pode ceder em face de outro, sem que seja necessária a declaração de invalidade jurídica do cedente ou a instituição de uma cláusula de exceção no suporte fático dele. As colisões entre princípios se resolvem mediante o estabelecimento de relações de precedência condicionada, as quais, conforme a chamada "lei de colisão", podem ser consagradas em enunciados normativos com a estrutura de regra. ${ }^{18}$ Tais enunciados, segundo a lei de colisão, expressam quais, entre os princípios colidentes, têm mais peso ou importância e, por isso, devem prevalecer sobre os outros, sob as circunstâncias do caso concreto. ${ }^{19}$

Princípios são, como visto, mandamentos de otimização, na medida em que exigem a realização de algo na maior medida possível relativamente às possibilidades fáticas e jurídicas do caso concreto. Segundo Alexy, essa definição de princípios está reciprocamente implicada com as três regras parciais ou subregras do exame de proporcionalidade: a adequação, a necessidade e a proporcionalidade em sentido estrito. As possibilidades fáticas de realização dos princípios se relacionam com as sub-regras da adequação e da necessidade, ao passo que as possibilidades jurídicas se relacionam com a sub-regra da proporcionalidade em sentido estrito.

As possibilidades jurídicas para a realização de um princípio são, dessa maneira, determinadas sobretudo pelos princípios colidentes, isto é, pelas normas de mesma natureza que impõem a realização de outro direito ou dever. Se uma norma com estrutura de princípio se contrapõe a outra, é necessário que se realize

\footnotetext{
${ }^{18}$ A lei de colisão pode ser enunciada da seguinte forma: "As condições sob as quais um princípio tem precedência em face de outro constituem o suporte fático de uma regra que expressa a consequência jurídica do princípio que tem precedência." (ALEXY, Robert. Teoria dos direitos fundamentais. Tradução de Virgílio Afonso da Silva. São Paulo: Malheiros, 2008. p. 99). Mais tecnicamente, ela também pode ser formulada assim: "Se o princípio P1 tem precedência em face do princípio P2 sob as condições C: (P1 P P2) C, e se do princípio P1, sob as condições C, decorre a consequência jurídica $R$, então, vale uma regra que tem $C$ como suporte fático e $R$ como consequência jurídica: C $\rightarrow$ R." (ALEXY, Robert. Teoria dos direitos fundamentais. Tradução de Virgílio Afonso da Silva. São Paulo: Malheiros, 2008. p. 99).

${ }^{19}$ Cf. ALEXY, Robert. Teoria dos direitos fundamentais. Tradução de Virgílio Afonso da Silva. São Paulo: Malheiros, 2008. p. 93-94.
} 
URBAN, Renan Lucas Dutra. Conflitos normativos e ponderação no novo código de processo civil: problemas teóricos, conceituais e metodológicos. Revista Eletrônica Direito e Política, Programa de Pós-Graduação Stricto Sensu em Ciência Jurídica da UNIVALI, Itajaí, v.14, n.1, $1^{\circ}$ quadrimestre de 2019. Disponível em: www.univali.br/direitoepolitica - ISSN 1980-7791

uma ponderação ou sopesamento, de modo que se determine qual delas deve ter primazia. A ponderação corresponde, assim, à sub-regra da proporcionalidade em sentido estrito, e conduz precisamente à definição do enunciado de precedência condicionada ou regra que soluciona a colisão entre princípios.

De acordo com Alexy, "quanto maior for o grau de não satisfação ou de afetação de um princípio, tanto maior terá que ser a importância da satisfação do outro." Esse raciocínio subjaz a toda ponderação entre princípios e sintetiza a assim denominada "lei do sopesamento". ${ }^{20}$ O enunciado da lei do sopesamento permite concluir que a ponderação é composta, basicamente, de três juízos: dois isolados - que dizem respeito ao exame do grau de não realização de um princípio e à análise da importância da realização do outro, que àquele se opõe - e um comparativo - que pressupõe os anteriores e consiste em verificar se a importância da satisfação de um princípio justifica o grau de não realização do outro. ${ }^{21}$

A ponderação destina-se, pois, à solução de colisões entre normas que se caracterizam como princípios. Quando dois ou mais princípios colidem entre si, sem que tenha sido estabelecido um enunciado de preferência condicionada predefinindo a solução para esse conflito normativo, o recurso à proporcionalidade e, por conseguinte, à ponderação será metodologicamente adequado. Do sopesamento entre princípios resultará, nos termos da lei de colisão, a regra que irá solucionar o problema. O sopesamento não será adequado ou suficiente, porém, quando já houver uma regra jurídica disciplinando essa colisão entre princípios. É que, nesse caso, não haverá um conflito entre princípios, mas, antes, um conflito entre um dos princípios e a regra, a exigir um tratamento metodológico diferenciado.

Uma regra, quando conflita com um princípio, geralmente veicula uma restrição ao suporte fático dele. Isso porque, nos termos da concepção teórica de Alexy, as possibilidades jurídicas de realização dos princípios jurídicos, ou mandamentos de

\footnotetext{
${ }^{20}$ ALEXY, Robert. Teoria dos direitos fundamentais. Tradução de Virgílio Afonso da Silva. São Paulo: Malheiros, 2008. p. 167.

${ }^{21}$ ALEXY, Robert. Teoria dos direitos fundamentais. Tradução de Virgílio Afonso da Silva. São Paulo: Malheiros, 2008. p. 594.
} 
URBAN, Renan Lucas Dutra. Conflitos normativos e ponderação no novo código de processo civil: problemas teóricos, conceituais e metodológicos. Revista Eletrônica Direito e Política, Programa de Pós-Graduação Stricto Sensu em Ciência Jurídica da UNIVALI, Itajaí, v.14, n.1, $1^{0}$ quadrimestre de 2019. Disponível em: www.univali.br/direitoepolitica - ISSN 1980-7791

otimização, são determinadas não apenas pelas normas de mesma estrutura colidentes, mas também pelas regras que preveem consequências jurídicas antagônicas para a mesma situação fática. ${ }^{22}$ Ora, regras jurídicas são sempre satisfeitas ou não satisfeitas, conforme tenham validade e aplicabilidade ou não. Dessa maneira, quando uma regra e um princípio preveem consequências jurídicas diferentes para um mesmo fato, o problema tende a se resolver com a simples aplicação da regra, por subsunção. ${ }^{23} \mathrm{~A}$ possibilidade de se discutir a validade jurídica da regra à luz do exame de proporcionalidade não muda esse raciocínio, uma vez que, na hipótese de ser considerada adequada, necessária e proporcional em sentido estrito - ou seja, proporcional em sentido amplo, ou materialmente legítima -, ela continuará precedendo o princípio na solução de problemas jurídicos, aplicando-se segundo a lógica "tudo ou nada". ${ }^{24}$

É de observar, porém, que há casos em que as regras, apesar de válidas - ou, quando menos, proporcionais em abstrato - se afiguram desproporcionais em concreto, prescrevendo uma solução subótima, injusta ou indesejada para situações fáticas que preenchem o suporte fático delas. ${ }^{25}$ Para a solução de casos desse tipo - que podem ser reconstruídos com colisões entre uma regra e um princípio -, certa proposta teórica defende que se recorra ao princípio material que fundamenta a regra, para o fim de que este seja sopesado com o princípio material que a ela contrapõe. ${ }^{26}$ Nesses termos, a depender do peso dos princípios materiais no caso concreto, a regra poderia ser derrotada ou superada pelo princípio

22 ALEXY, Robert. Teoria dos direitos fundamentais. Tradução de Virgílio Afonso da Silva. São Paulo: Malheiros, 2008. p. 90.

23 LIMA, Rafael Scavone Bellem de. Otimização de princípios, separação dos poderes e segurança jurídica: o conflito entre regra e princípio. 2012. 157 f. Dissertação (Mestrado em Direito) - Faculdade de Direito, Universidade de São Paulo, São Paulo, 2012. p. 43.

${ }^{24}$ SILVA, Virgílio Afonso da. Direitos fundamentais: conteúdo essencial, restrições, eficácia. 2. ed. São Paulo: Malheiros, 2010. p. 52-53.

25 Cf. URBAN, Renan Lucas Dutra. Colisões entre regras e princípios, otimização e derrotabilidade: o caráter definitivo das regras. 2017. 100 f. Dissertação (Mestrado em Direito) Faculdade de Ciências Humanas e Sociais, Universidade Estadual Paulista "Júlio de Mesquita Filho", Franca, 2017. p. 52-58. Acerca do caráter sobreinclusivo e subinclusivo das generalizações prescritivas - isto é, das regras jurídicas -, cf. SCHAUER, Frederick. Playing by the rules: a philosophical examination of rule-based decision-making in law and in life. New York: Oxford University Press, 2002. p. 31-37.

${ }^{26}$ Essa proposta define a própria posição de Alexy a respeito do problema. Cf. ALEXY, Robert. Teoria dos direitos fundamentais. Tradução de Virgílio Afonso da Silva. São Paulo: Malheiros, 2008. p. 90, nota de rodapé n. 24. 
URBAN, Renan Lucas Dutra. Conflitos normativos e ponderação no novo código de processo civil: problemas teóricos, conceituais e metodológicos. Revista Eletrônica Direito e Política, Programa de Pós-Graduação Stricto Sensu em Ciência Jurídica da UNIVALI, Itajaí, v.14, n.1, $1^{0}$ quadrimestre de 2019. Disponível em: www.univali.br/direitoepolitica - ISSN 1980-7791

colidente. ${ }^{27}$ Tal tese, no entanto, é problemática. Virgílio Afonso da Silva, por exemplo, afirma que sua adoção implica aceitar a ideia de que "[...] o aplicador do direito está sempre livre, em qualquer caso e em qualquer situação, para afastar a aplicação de uma regra por entender que há um princípio mais importante que justifica esse afastamento."28

Neste ponto, convém ressaltar um ponto trivial, mas muitas vezes despercebido: as regras jurídicas postas no ordenamento jurídico são o produto da aplicação do exame de proporcionalidade por órgãos investidos de legitimidade democrática e/ou dotados de capacidade técnica específica. Elas correspondem a enunciados de precedência condicionada, resultantes de ponderações entre princípios efetuadas pelo legislador - ou por outra instância normativa, responsável pela elaboração do Direito. De fato, não só o Poder Judiciário aplica a proporcionalidade e pondera princípios; também o Poder Legislativo o faz, fixando, em nível abstrato, soluções para situações de colisão entre normas desse tipo. Tais soluções legislativas concretizam-se, basicamente, em regras infraconstitucionais, que "[...] proíbem alguma conduta que é permitida prima facie por algum direito fundamental, ou autorizam alguma ação estatal cujo efeito é a restrição da proteção que um direito fundamental prima facie garantia." 29

As regras jurídicas gerais-abstratas, portanto, veiculam a solução concebida pelos órgãos normativos para determinado caso concreto - solução esta que, em Estados democráticos, não pode ser livremente substituída por outra, proveniente, por exemplo, do Poder Judiciário. ${ }^{30}$ As regras, então, podem ser consideradas

\footnotetext{
27 Remete-se, aqui, à ideia de derrotabilidade (defeasibility), que, conforme os pressupostos deste trabalho, pode ser definida como a possibilidade de que uma regra, desproporcional sob as circunstâncias de um caso concreto, seja excepcionada, de maneira que o resultado subótimo, infeliz ou indesejado, por ela prescrito para esse caso, não seja produzido. Cf., sobre tal conceito de derrotabilidade, URBAN, Renan Lucas Dutra. Colisões entre regras e princípios, otimização e derrotabilidade: o caráter definitivo das regras. 2017. 100 f. Dissertação (Mestrado em Direito) Faculdade de Ciências Humanas e Sociais, Universidade Estadual Paulista "Júlio de Mesquita Filho", Franca, 2017. p. 58-63.

28 SILVA, Virgílio Afonso da. Direitos fundamentais: conteúdo essencial, restrições, eficácia. 2. ed. São Paulo: Malheiros, 2010. p. 52.

29 SILVA, Virgílio Afonso da. Direitos fundamentais: conteúdo essencial, restrições, eficácia. 2. ed. São Paulo: Malheiros, 2010. p. 141.
}

30 ÁVILA, Humberto. Teoria dos princípios: da definição à aplicação dos princípios jurídicos. 7. ed. São Paulo: Malheiros, 2007. p. 103. 
URBAN, Renan Lucas Dutra. Conflitos normativos e ponderação no novo código de processo civil: problemas teóricos, conceituais e metodológicos. Revista Eletrônica Direito e Política, Programa de Pós-Graduação Stricto Sensu em Ciência Jurídica da UNIVALI, Itajaí, v.14, n.1, ${ }^{\circ}$ quadrimestre de 2019. Disponível em: www.univali.br/direitoepolitica - ISSN 1980-7791

instrumentos de alocação de poder, na medida em que limitam a liberdade dos órgãos julgadores para decidir com base em princípios. ${ }^{31}$

Além disso, pelo fato de que definem, de antemão, o que é juridicamente devido em caráter definitivo, as regras afastam os casuísmos e reduzem as incertezas que geralmente resultam da ausência delas. Diferentemente dos princípios, cujo conteúdo deve ser otimizado em relação às possibilidades fáticas e jurídicas, as regras não têm sua aplicação sujeita a uma análise das condições de cada caso concreto. As regras tendem a diminuir o número de fatores que tem de ser levado em consideração pelos órgãos julgadores, simplificando o processo de tomada de decisão. Assim, no contexto das sociedades plurais e complexas, pode-se dizer que elas cumprem a importante função de tornar mais previsível e confiável a solução dos casos concretos, além de trazer mais eficiência ao processo decisório. ${ }^{32}$

Há razões suficientemente fortes, portanto, para se sustentar que as regras, precisamente pelo fato de que possuem um caráter definitivo, devem oferecer uma resistência à sua superação por princípios colidentes muito mais forte do que aquela que é oferecida pelos princípios. ${ }^{33}$ Como nota Humberto Ávila, as regras têm uma "função eficacial de trincheira", dado a circunstância de que, em comparação com os princípios, opõem um obstáculo à superação muito mais difícil de ser transposto. ${ }^{34}$ Isso significa que, em boa parte dos casos, uma regra válida

31 Cf., nesse sentido, LIMA, Rafael Scavone Bellem de. Otimização de princípios, separação dos poderes e segurança jurídica: o conflito entre regra e princípio. 2012. 157 f. Dissertação (Mestrado em Direito) - Faculdade de Direito, Universidade de São Paulo, São Paulo, 2012. p. 6366.

${ }^{32} \mathrm{Cf}$., sobre a relação entre a aplicação das regras e a promoção de certos princípios formais - como os da competência decisória do legislador, da segurança jurídica e da eficiência decisória -, LIMA, Rafael Scavone Bellem de. Otimização de princípios, separação dos poderes e segurança jurídica: o conflito entre regra e princípio. 2012. 157 f. Dissertação (Mestrado em Direito) Faculdade de Direito, Universidade de São Paulo, São Paulo, 2012. p. 60-66; URBAN, Renan Lucas Dutra. Colisões entre regras e princípios, otimização e derrotabilidade: o caráter definitivo das regras. 2017. 100 f. Dissertação (Mestrado em Direito) - Faculdade de Ciências Humanas e Sociais, Universidade Estadual Paulista "Júlio de Mesquita Filho", Franca, 2017. p. 73-84.

33 LIMA, Rafael Scavone Bellem de. Otimização de princípios, separação dos poderes e segurança jurídica: o conflito entre regra e princípio. 2012. 157 f. Dissertação (Mestrado em Direito) - Faculdade de Direito, Universidade de São Paulo, São Paulo, 2012. p. 54.

34 ÁVILA, Humberto. Teoria dos princípios: da definição à aplicação dos princípios jurídicos. 7. ed. São Paulo: Malheiros, 2007. p. 103. 
URBAN, Renan Lucas Dutra. Conflitos normativos e ponderação no novo código de processo civil: problemas teóricos, conceituais e metodológicos. Revista Eletrônica Direito e Política, Programa de Pós-Graduação Stricto Sensu em Ciência Jurídica da UNIVALI, Itajaí, v.14, n.1, $1^{0}$ quadrimestre de 2019. Disponível em: www.univali.br/direitoepolitica - ISSN 1980-7791

e aplicável cuja aplicação leva à produção de um resultado infeliz não pode ser afastada para que, no seu lugar, seja aplicado um princípio colidente, cuja consequência jurídica corresponde ao resultado considerado ótimo ou ideal pelo tomador de decisão. Dessa maneira, pode-se dizer que, nas situações concretas em que uma regra e um princípio colidem, aquela, no mais das vezes, tem primazia, devendo ser aplicada em detrimento da aplicação deste.

Como visto, o exame de proporcionalidade e sua terceira sub-regra, a ponderação, possuem uma finalidade específica - resolver casos que devem ser solucionados por meio da aplicação de princípios -, não se confundindo com as técnicas de argumentação jurídica em geral. ${ }^{35}$ A utilização da proporcionalidade e da ponderação no lugar de outras formas de aplicação do Direito, como a subsunção, pode levar a uma banalização das complexas questões referentes a princípios e regras, ${ }^{36}$ redundando em problemas de segurança jurídica, de eficiência e de alocação de poder, entre outros. ${ }^{37}$

A despeito disso, o modelo teórico - já bastante difundido na prática jurídica brasileira - que defende a utilização do sopesamento entre princípios materiais como forma de solucionar colisões entre uma regra e um princípio não parece considerar o papel específico desempenhado pelas regras no ordenamento jurídico. Ou seja, ela parece ignorar que "[...] a decisão pela superação de uma regra não afeta apenas a realização dos princípios que são fomentados ou

35 Cf. BARCELLOS, Ana Paula de. Ponderação, racionalidade e atividade jurisdicional. Rio de Janeiro: Renovar, 2005. p. 27-35.

36 NEVES, Marcelo. Entre Hidra e Hércules: princípios e regras constitucionais como diferença paradoxal do sistema jurídico. São Paulo: WMF Martins Fontes, 2013. p. 171.

37 Nesse sentido, Humberto Ávila, criticando as premissas do chamado "neoconstitucionalismo", apresenta três razões pelas quais a ponderação não poderia servir como critério geral de aplicação do Direito. Em primeiro lugar, o paradigma da ponderação culmina num "anti-escalonamento" do sistema jurídico, pois torna os princípios diretamente aplicáveis a toda situação, em detrimento dos diversos outros níveis de concretização normativa. Em segundo lugar, o recurso à ponderação, ao permitir que regras válidas, diretamente aplicáveis a determinada situação concreta, sejam afastadas em favor da satisfação de princípios, implica uma desvalorização do papel e da importância do Poder Legislativo nas sociedades democráticas. Por fim, o sopesamento conduz, segundo Ávila, a uma espécie de subjetivismo, cuja consequência é a redução ou mesmo a eliminação do caráter heterolimitador do Direito. Cf. ÁVILA, Humberto. "Neoconstitucionalismo": entre a ciência do direito e o direito da ciência. Revista Eletrônica do Direito do Estado (REDE), Salvador, n. 17, jan./fev./mar. 2009. Disponível em: <www.direitodoestado.com.br/rede.asp>. Acesso em: 03 de julho de 2018. p. 7-12. 
URBAN, Renan Lucas Dutra. Conflitos normativos e ponderação no novo código de processo civil: problemas teóricos, conceituais e metodológicos. Revista Eletrônica Direito e Política, Programa de Pós-Graduação Stricto Sensu em Ciência Jurídica da UNIVALI, Itajaí, v.14, n.1, $1^{\circ}$ quadrimestre de 2019. Disponível em: www.univali.br/direitoepolitica - ISSN 1980-7791

restringidos por essa norma, mas também a alocação da competência decisória e a previsibilidade da aplicação do direito."

A utilização do sopesamento para afastar a aplicação de uma regra não se compatibiliza com a ideia de precedência prima facie que, nas situações concretas, essas normas devem ter em relação aos princípios. ${ }^{39} \mathrm{O}$ afastamento de uma regra aplicável a uma situação concreta só pode ser admitido em caráter excepcional, com enfrentamento, pelo órgão julgador, da carga argumentativa que a hipótese impõe. Mas o recurso ao sopesamento entre determinados princípios materiais não condiciona o afastamento da regra a circunstâncias excepcionais, anômalas. Por isso, em última análise, ele representa uma ingerência do Poder Judiciário na esfera de competência dos demais poderes, na medida em que, como afirma Virgílio Afonso da Silva, autoriza o órgão julgador a afastar a aplicação da regra sempre que entender que há um princípio mais importante a justificar esse afastamento.

\subsection{Os Ônus de Fundamentação Impostas Pela Proporcionalidade e Pela Ponderação}

A proporcionalidade (em sentido amplo) dirigem importantes ônus argumentativos ao aplicador do Direito. Como assinalado, a ponderação, como uma das sub-regras do exame de proporcionalidade, guia-se por uma "lei do sopesamento", que expressa a ideia de que "quanto maior for o grau de não satisfação ou de afetação de um princípio, tanto maior terá que ser a importância da satisfação do outro."

\footnotetext{
38 LIMA, Rafael Scavone Bellem de. Otimização de princípios, separação dos poderes e segurança jurídica: o conflito entre regra e princípio. 2012. 157 f. Dissertação (Mestrado em Direito) - Faculdade de Direito, Universidade de São Paulo, São Paulo, 2012. p. 67.

39 Nos termos de Rafael Bellem de Lima, "[...] as regras devem ter precedência prima facie sobre os princípios, ou seja, a sua resistência à superação por meio de decisões judiciais individuais deve ser superior à das normas que devem ser realizadas na maior medida possível dentro das possibilidades fáticas e jurídicas do caso concreto." (LIMA, Rafael Scavone Bellem de. Otimização de princípios, separação dos poderes e segurança jurídica: o conflito entre regra e princípio. 2012. $157 \mathrm{f}$. Dissertação (Mestrado em Direito) - Faculdade de Direito, Universidade de São Paulo, São Paulo, 2012. p. 73).

40 ALEXY, Robert. Teoria dos direitos fundamentais. Tradução de Virgílio Afonso da Silva. São Paulo: Malheiros, 2008. p. 167.
} 
URBAN, Renan Lucas Dutra. Conflitos normativos e ponderação no novo código de processo civil: problemas teóricos, conceituais e metodológicos. Revista Eletrônica Direito e Política, Programa de Pós-Graduação Stricto Sensu em Ciência Jurídica da UNIVALI, Itajaí, v.14, n.1, $1^{\circ}$ quadrimestre de 2019. Disponível em: www.univali.br/direitoepolitica - ISSN 1980-7791

A lei do sopesamento consubstancia um modelo fundamentado das relações de precedência condicionada, o qual, à diferença de um modelo decisionista, "[...] distingue entre o processo psíquico que conduz à definição do enunciado de preferência e sua fundamentação." ${ }^{41}$ De acordo com Alexy, pode-se proceder a essa fundamentação dos enunciados de preferência com o auxílio de uma escala de três níveis, que conduz a uma categorização dos graus de afetação e de importância dos princípios colidentes em "pequenos", "médios" e "grandes". ${ }^{42} \mathrm{~A}$ solução para uma colisão entre princípios, nesses termos, não resulta de uma valoração livre, mas de um "procedimento de justificação", 43 o qual, se não leva, em todo e qualquer caso, a uma conclusão única e inequívoca, ao menos fornece parâmetros para uma maior racionalidade e objetividade na argumentação jurídica, garantindo ou ampliando a possibilidade de controle intersubjetivo das decisões. ${ }^{44}$

A lei do sopesamento, portanto, não oferece uma pauta material para a solução das colisões entre princípios. ${ }^{45}$ Em outras palavras, ela não descreve um modelo capaz de levar a uma avaliação inequívoca da correção das decisões. Ela veicula, porém, uma exigência de fundamentação das relações condicionadas de precedência, estabelecendo um procedimento para a justificação racional das decisões ponderativas. Ao pressupor um escalonamento dos graus de restrição e de realização das normas com estrutura de princípios, ${ }^{46}$ a aplicação da ponderação dirige, em suma, um importante ônus argumentativo ao aplicador do Direito,

\footnotetext{
${ }^{41}$ ALEXY, Robert. Teoria dos direitos fundamentais. Tradução de Virgílio Afonso da Silva. São Paulo: Malheiros, 2008. p. 165.

42 Esse escalonamento permite construir uma "fórmula do peso", que expressa o peso concreto do princípio em face do princípio colidente. Cf. ALEXY, Robert. La fórmula del peso. In: CARBONELL, Miguel (Coord.). El principio de proporcionalidad en el Estado constitucional. Bogotá: Universidad Externado de Colombia, 2007. p. 15-49.
}

43 CLÉRICO, Laura. El examen de proporcionalidad em el derecho constitucional. Buenos Aires: Universidad de Buenos Aires, 2009. p. 594.

44 Nesse sentido, cf. SILVA, Virgílio Afonso da. Ponderação e objetividade na interpretação constitucional. In: MACEDO JUNIOR, Ronaldo Porto; BARBIERI, Catarina Helena Cortada (Org.). Direito e interpretação: racionalidades e instituições. São Paulo: Direito GV/Saraiva, 2011. p. 366389.

45 CLÉRICO, Laura. El examen de proporcionalidad em el derecho constitucional. Buenos Aires: Universidad de Buenos Aires, 2009. p. 196.

${ }^{46}$ Cf. ALEXY, Robert. Teoria dos direitos fundamentais. Tradução de Virgílio Afonso da Silva. São Paulo: Malheiros, 2008. p. 585-611. 
URBAN, Renan Lucas Dutra. Conflitos normativos e ponderação no novo código de processo civil: problemas teóricos, conceituais e metodológicos. Revista Eletrônica Direito e Política, Programa de Pós-Graduação Stricto Sensu em Ciência Jurídica da UNIVALI, Itajaí, v.14, n.1, 10 quadrimestre de 2019. Disponível em: www.univali.br/direitoepolitica - ISSN 1980-7791

impondo-Ihe o dever de explicitar, de modo adequado, os pesos atribuídos a cada um dos princípios colidentes. ${ }^{47}$

Mas a proporcionalidade não importa apenas sopesar os princípios materiais em colisão; ela também implica indagar acerca da adequação e da necessidade da medida de intervenção, hipotética ou real, cuja legitimidade material é examinada. Em outras palavras, sua aplicação exige, em primeiro lugar, uma análise sobre a aptidão da medida para fomentar o fim a que se preordena (teste da adequação ou idoneidade técnica); em segundo lugar, uma avaliação sobre a existência de uma medida alternativa que seja, ao mesmo tempo, pelo menos igualmente adequada e menos desvantajosa para o princípio afetado (teste da necessidade); e, apenas por último, uma comparação entre a intensidade da intervenção no âmbito de proteção do princípio e a importância da realização do princípio que com ele colide (teste da proporcionalidade em sentido estrito, ou ponderação). ${ }^{48}$

O exame de proporcionalidade possui, como se vê, uma estrutura complexa, compondo-se de três regras parciais ou sub-regras; além disso, possui uma estrutura ordenada, já que tais sub-regras se encadeiam sucessivamente. O teste da proporcionalidade em sentido estrito não pode anteceder os da necessidade e da adequação, e o teste da necessidade não pode preceder o da adequação. Adequação, necessidade e proporcionalidade em sentido estrito correspondem, respectivamente, à primeira, à segunda e à terceira sub-regras da proporcionalidade, e nessa ordem devem ser aplicadas.

Como salienta Virgílio Afonso da Silva, "a real importância dessa ordem fica patente quando se tem em mente que a aplicação da regra da proporcionalidade nem sempre implica a análise de todas as suas três sub-regras." ${ }^{49}$ Isso decorre do fato de que essas regras parciais guardam, entre si, uma relação de

47 Cf., nesse sentido, SILVA, Virgílio Afonso da. Ponderação e objetividade na interpretação constitucional. In: MACEDO JUNIOR, Ronaldo Porto; BARBIERI, Catarina Helena Cortada (Org.). Direito e interpretação: racionalidades e instituições. São Paulo: Direito GV/Saraiva, 2011. p. 369372.

48 Sobre o conteúdo das sub-regras da proporcionalidade, cf. SILVA, Virgílio Afonso da. O proporcional e o razoável. Revista dos Tribunais, São Paulo, ano 91, n. 798, abr. 2002. p. 36-42.

49 SILVA, Virgílio Afonso da. O proporcional e o razoável. Revista dos Tribunais, São Paulo, ano 91, n. 798 , abr. 2002. p. 34. 
URBAN, Renan Lucas Dutra. Conflitos normativos e ponderação no novo código de processo civil: problemas teóricos, conceituais e metodológicos. Revista Eletrônica Direito e Política, Programa de Pós-Graduação Stricto Sensu em Ciência Jurídica da UNIVALI, Itajaí, v.14, n.1, ${ }^{\circ}$ quadrimestre de 2019. Disponível em: www.univali.br/direitoepolitica - ISSN 1980-7791

prejudicialidade. Desse modo, até por razões de eficiência decisória, só cabe analisar a necessidade de uma medida de intervenção se se considerar que ela é adequada; além disso, só se torna necessário proceder ao exame da proporcionalidade em sentido estrito se se concluir que ela é necessária e adequada. A reprovação da medida em algum dos testes da proporcionalidade já é suficiente para que ela seja considerada desproporcional em sentido amplo, dispensando, portanto, a aplicação do(s) teste(s) restante(s).

O exame de proporcionalidade, considerado em sentido amplo, é uma forma de aplicação e interpretação do Direito que busca introduzir alguma objetividade e racionalidade na fundamentação das decisões jurídicas. À semelhança da proporcionalidade em sentido estrito, sua importância do ponto de vista metodológico está relacionada ao endereçamento de ônus argumentativos ao Poder Público, que fica obrigado a fundamentar toda intervenção no âmbito de proteção dos princípios. Sua aplicação aponta, assim, para um modo concreto de pensar os problemas jurídicos, que evidencia e reforça a dimensão argumentativa do Direito.

Portanto, a proporcionalidade e, particularmente, a ponderação não são métodos matemáticos, capazes de conduzir, sempre, à (única) solução correta para todos os casos. Possuem, contudo, uma estrutura complexa e bem definida, que, ao impor ônus de argumentação ao aplicador do Direito, expõe as decisões com base neles proferidas a um controle intersubjetivo comparativamente superior a outros métodos. 50

$50 \mathrm{Cf}$., nesse sentido, BOROWSKI, Martin. La estructura de los derechos fundamentales. Tradução de Carlos Bernal Pulido. Bogotá: Universidad Externado de Colombia, 2003, p. 57. Cf., na mesma linha, BERNAL PULIDO, Carlos. El principio de proporcionalidad y los derechos fundamentales. 3. ed. Madrid: Centro de Estudios Políticos y Constitucionales, 2007. p. 71-72: "A pesar de que sea preciso tomar en serio la objeción que imputa a la aplicación del princípio de proporcionalidad una carencia de puntos de referencia objetivos, ésta no parece revestir la contundencia suficiente para desvirtuar la posibilidad de utilizar este principio en la interpretación de los derechos fundamentales. La carencia de objetividad o de racionalidad absoluta no se presentea sólo cuando se practica la ponderación, o de manera más amplia, cuando se aplica el principio de proporcionalidad, sino siempre que debe llevarse a cabo un razonamiento jurídico mediante el cual deban resolverse cuestiones normativas. Por lo tanto, esta carencia afecta también a la aplicación de los criterios alternativos al principio de proporcionalidad, mediante la cual se pretende resolver asimismo la cuestión normativa, de si una determinada intervención del Legislador en un derecho fundamental debe ser considerada constitucionalmente admisible, o técnicamente, de si puede fundamentarse la validez de una norma adscrita de contenido contrario al de la ley examinada. Dada 
URBAN, Renan Lucas Dutra. Conflitos normativos e ponderação no novo código de processo civil: problemas teóricos, conceituais e metodológicos. Revista Eletrônica Direito e Política, Programa de Pós-Graduação Stricto Sensu em Ciência Jurídica da UNIVALI, Itajaí, v.14, n.1, ${ }^{\circ}$ quadrimestre de 2019. Disponível em: www.univali.br/direitoepolitica - ISSN 1980-7791

No entanto, como assinalado, nem sempre juízes e tribunais se valem de tais categorias com o rigor metodológico necessário. O recurso inadequado à ponderação como forma de solução dos conflitos normativos é uma das principais críticas que, no terreno da metodologia jurídica, podem ser feitas à prática jurídica brasileira. Nessa esteira, alguns autores apontam para um problema de fundamentação das decisões judiciais, decorrente do não enfrentamento, pelos órgãos julgadores, dos ônus argumentativos estabelecidos pelas sub-regras do exame de proporcionalidade. Virgílio Afonso da Silva, por exemplo, observa haver, muitas vezes, uma invocação meramente retórica da regra da proporcionalidade pelo Supremo Tribunal Federal, como se a simples menção a essa forma de aplicação do Direito fosse, por si só, suficiente para justificar as decisões tomadas. ${ }^{51}$ No mesmo sentido, ressalta Rafael Bellem de Lima que o recurso à proporcionalidade, no caso brasileiro, "[...] tende a ser inconstante, pouco fundamentado, incoerente e, muitas vezes, meramente retórico, funcionando apenas como um argumento adicional para fundamentar uma decisão préconcebida pelo julgador."52

esta circunstancia, como ya hemos señalado, el problema no consiste en indagar si la aplicación del principio de proporcionalidad puede sustentarse en argumentaciones que la hagan objetiva, sino, si mediante la aplicación de dicho principio puede alcanzarse una maior racionalidad relativa, en comparación con aquélla que se logra cuando se aplican los criterios alternativos." Cf., também, SILVA, Virgílio Afonso da. Ponderação e objetividade na interpretação constitucional. In: MACEDO JUNIOR, Ronaldo Porto; BARBIERI, Catarina Helena Cortada (Org.). Direito e interpretação: racionalidades e instituições. São Paulo: Direito GV/Saraiva, 2011. p. 378: "[...] parece-me possível afirmar que não existe objetividade absoluta e demonstrável, mas que existe, sim, a possibilidade de uma objetividade em um sentido mais fraco. Essa 'objetividade possível' depende, a meu ver, da conjugação dos três aspectos que tentei brevemente analisar até aqui: o metodológico, o teórico e o institucional. Parece-me que essa conjugação é imprescindível para escapar do maniqueísmo expresso pela frase 'o método a é melhor do que o método $b$ '. Se se levam a sério os argumentos desenvolvidos quando da análise dessas três premissas, parece-me que é possível, sim, que o sopesamento possa desempenhar um papel preponderante - e, sobretudo, racional e objetivo - na interpretação constitucional. Aquele que imagina que objetividade tem que ser algo mais do que isso, ou que há métodos mais objetivos e racionais que o sopesamento e que, ao mesmo tempo, sejam adequados para a interpretação e a aplicação dos direitos fundamentais em um Estado constitucional contemporâneo tem o ônus para demonstrar a viabilidade metodológica, teórica e institucional dessa suposição."

${ }^{51}$ SILVA, Virgílio Afonso da. O proporcional e o razoável. Revista dos Tribunais, São Paulo, ano 91, n. 798, abr. 2002. p. 31-34.

52 LIMA, Rafael Scavone Bellem de. Otimização de princípios, separação dos poderes e segurança jurídica: o conflito entre regra e princípio. 2012. 157 f. Dissertação (Mestrado em Direito) - Faculdade de Direito, Universidade de São Paulo, São Paulo, 2012. p. 80. Para um estudo da forma pela qual a proporcionalidade é utilizada no âmbito da jurisprudência do Supremo Tribunal Federal - com ênfase nas decisões proferidas por um de seus membros, o Ministro Gilmar Mendes , cf. PEREIRA, Bruno Ramos. O uso da proporcionalidade no Supremo Tribunal Federal: análise 
URBAN, Renan Lucas Dutra. Conflitos normativos e ponderação no novo código de processo civil: problemas teóricos, conceituais e metodológicos. Revista Eletrônica Direito e Política, Programa de Pós-Graduação Stricto Sensu em Ciência Jurídica da UNIVALI, Itajaí, v.14, n.1, $1^{\circ}$ quadrimestre de 2019. Disponível em: www.univali.br/direitoepolitica - ISSN 1980-7791

A despreocupação metodológica em torno da proporcionalidade e da ponderação enseja a produção de decisões casuísticas e voluntaristas, contrariando o objetivo da teoria dos princípios de fixar parâmetros argumentativos para uma maior controlabilidade das decisões. De resto, ela contribui para a consolidação da ideia - evidentemente equivocada para os adeptos da teoria de Alexy - de que tais categorias teóricas são topoi dotados de um caráter meramente retórico, podendo ser utilizados para sustentar qualquer solução ou tese. ${ }^{53}$

\section{CONSIDERAÇÕES FINAIS}

O artigo 489, parágrafo segundo, do novo Código de Processo Civil estabelece um dever genérico de fundamentação das decisões judiciais que, por meio da ponderação, resolvem conflitos normativos. Além das críticas - aqui não analisadas - que podem ser feitas à defeituosa redação desse dispositivo, o presente trabalho concentrou seu foco em duas linhas críticas já conhecidas, que apontam, respectivamente, para o suposto caráter subjetivo ou discricionário das decisões proferidas com base no sopesamento e para a falta de rigor conceitual e metodológico com que, muitas vezes, os órgãos julgadores recorrem a essa específica forma de aplicação e de interpretação do Direito para solucionar casos concretos.

Cumpre ressaltar, aqui, a relevância da primeira linha crítica. Mesmo que não se adira à ideia de Friedrich Müller, por exemplo, de que a ponderação expressa simples preferências ideológicas do intérprete, ou não se encampe a objeção de

dos votos do ministro Gilmar Mendes. 2009. 112 f. Dissertação (Mestrado em Direito) - Faculdade de Direito, Universidade de São Paulo, São Paulo, 2009. Ainda sobre os déficits de fundamentação que decorrem do modo com que o Supremo Tribunal Federal geralmente invoca a teoria dos princípios para fundamentar suas decisões, cf. GORZONI, Paula Fernanda Alves da Cunha. Ponderação e critérios racionais de decidibilidade na argumentação judicial. $2011.98 \mathrm{f}$. Dissertação (Mestrado em Direito) - Faculdade de Direito, Universidade de São Paulo, São Paulo, 2011. p. 87-88.

53 Cf., nesse sentido, SILVA, Virgílio Afonso da. O proporcional e o razoável. Revista dos Tribunais, São Paulo, ano 91, n. 798, abr. 2002. p. 31. Acerca do pensamento tópico e do emprego de lugarescomuns - também chamados loci ou topoi - na argumentação jurídica, cf. FERRAZ JUNIOR, Tércio Sampaio. Introdução ao estudo do direito: técnica, decisão, dominação. 4. ed. São Paulo: Atlas, 2003. p. 327-331. 
URBAN, Renan Lucas Dutra. Conflitos normativos e ponderação no novo código de processo civil: problemas teóricos, conceituais e metodológicos. Revista Eletrônica Direito e Política, Programa de Pós-Graduação Stricto Sensu em Ciência Jurídica da UNIVALI, Itajaí, v.14, n.1, $1^{\circ}$ quadrimestre de 2019. Disponível em: www.univali.br/direitoepolitica - ISSN 1980-7791

Habermas, segundo a qual o sopesamento, guiado pela noção de "ordem objetiva de valores", pode levar a um sacrifício dos direitos fundamentais em face de interesses coletivos, é inegável que tais autores - e outros mais que contestam a racionalidade e a objetividade das decisões ponderativas - contribuem decisivamente para a ampliação do debate acerca das premissas e implicações da teoria dos princípios de Robert Alexy - algo de significativa importância sobretudo quando se tem vista o fato de que tal modelo teórico vem sendo amplamente recepcionado, sem a necessária reflexão, em diversos países, incluindo o Brasil.

É de ressaltar, também, a importância da segunda vertente crítica, que baseia suas objeções nos casuísmos e abusos que muitas vezes resultam da utilização inadequada das categorias da teoria dos princípios. Nesse particular, destaque-se sobretudo a objeção levantada pelos autores que problematizam a questão da superabilidade ou derrotabilidade das regras, mostrando os riscos inerentes a uma argumentação baseada exclusivamente em princípios para a segurança jurídica, para a eficiência decisória e para o modelo de distribuição de competências desenhado na ordem jurídico-constitucional.

\section{REFERÊNCIAS DAS FONTES CITADAS}

ALEXY, Robert. Constitutional rights, balancing and rationality. Ratio Juris, Oxford, v. 16, n. 2, jun. 2003.

La fórmula del peso. In: CARBONELL, Miguel (Coord.). El principio de proporcionalidad en el Estado constitucional. Bogotá: Universidad Externado de Colombia, 2007.

Teoria dos direitos fundamentais. Tradução de Virgílio Afonso da Silva. São Paulo: Malheiros, 2008.

ÁVILA, Humberto. Teoria dos princípios: da definição à aplicação dos princípios jurídicos. 7. ed. São Paulo: Malheiros, 2007.

"Neoconstitucionalismo": entre a ciência do direito e o direito da ciência.

Revista Eletrônica do Direito do Estado (REDE), Salvador, n. 17, jan./fev./mar. 2009. Disponível em: <www.direitodoestado.com.br/rede.asp>. Acesso em: 03 de julho de 2018. 
URBAN, Renan Lucas Dutra. Conflitos normativos e ponderação no novo código de processo civil: problemas teóricos, conceituais e metodológicos. Revista Eletrônica Direito e Política, Programa de Pós-Graduação Stricto Sensu em Ciência Jurídica da UNIVALI, Itajaí, v.14, n.1, $1^{\circ}$ quadrimestre de 2019. Disponível em: www.univali.br/direitoepolitica - ISSN 1980-7791

BANDEIRA DE MELLO, Celso Antônio. Curso de direito administrativo. 23. ed. São Paulo: Malheiros, 2007.

BARCELLOS, Ana Paula de. Ponderação, racionalidade e atividade jurisdicional. Rio de Janeiro: Renovar, 2005.

BERNAL PULIDO, Carlos. El principio de proporcionalidad y los derechos fundamentales. 3. ed. Madrid: Centro de Estudios Políticos y Constitucionales, 2007.

BOROWSKI, Martin. La estructura de los derechos fundamentales. Tradução de Carlos Bernal Pulido. Bogotá: Universidad Externado de Colombia, 2003.

BRASIL. Lei n. 13.105 de 16 de março de 2015. Código de Processo Civil. Diário Oficial da União. Poder Executivo, Brasília, DF, 17/03/2015, p. 1. Disponível em: <www.planalto.gov.br/ccivil_03/_Ato2015-2018/2015/Lei/L13105.htm>. Acesso em: 16 de setembro de 2018.

CLÉRICO, Laura. El examen de proporcionalidad em el derecho constitucional. Buenos Aires: Universidad de Buenos Aires, 2009.

FERRAZ JUNIOR, Tércio Sampaio. Introdução ao estudo do direito: técnica, decisão, dominação. 4. ed. São Paulo: Atlas, 2003.

GORZONI, Paula Fernanda Alves da Cunha. Ponderação e critérios racionais de decidibilidade na argumentação judicial. 2011. 98 f. Dissertação (Mestrado em Direito) - Faculdade de Direito, Universidade de São Paulo, São Paulo, 2011.

HABERMAS, Jürgen. Direito e democracia: entre facticidade e validade. Tradução de Flávio Beno Siebneichler. Rio de Janeiro: Tempo Brasileiro, 1997, v. 1.

LIMA, Rafael Scavone Bellem de. Otimização de princípios, separação dos poderes e segurança jurídica: o conflito entre regra e princípio. 2012. $157 \mathrm{f}$. Dissertação (Mestrado em Direito) - Faculdade de Direito, Universidade de São Paulo, São Paulo, 2012.

MENDES, Conrado Hübner. Direitos fundamentais, separação dos poderes e deliberação. 2008. 267 f. Tese (Doutorado em Ciência Política) - Faculdade de Filosofia, Letras e Ciências Humanas, Universidade de São Paulo, São Paulo, 2008.

MÜLLER, Friedrich. Métodos de trabalho do direito constitucional. Tradução de Peter Naumann. 3. ed. Rio de Janeiro: Renovar, 2005.

NEVES, Marcelo. Entre Hidra e Hércules: princípios e regras constitucionais como diferença paradoxal do sistema jurídico. São Paulo: WMF Martins Fontes, 2013.

PEREIRA, Bruno Ramos. O uso da proporcionalidade no Supremo Tribunal Federal: análise dos votos do ministro Gilmar Mendes. 2009. 112 f. Dissertação 
URBAN, Renan Lucas Dutra. Conflitos normativos e ponderação no novo código de processo civil: problemas teóricos, conceituais e metodológicos. Revista Eletrônica Direito e Política, Programa de Pós-Graduação Stricto Sensu em Ciência Jurídica da UNIVALI, Itajaí, v.14, n.1, $1^{\circ}$ quadrimestre de 2019. Disponível em: www.univali.br/direitoepolitica - ISSN 1980-7791

(Mestrado em Direito) - Faculdade de Direito, Universidade de São Paulo, São Paulo, 2009.

SCHAUER, Frederick. Playing by the rules: a philosophical examination of rulebased decision-making in law and in life. New York: Oxford University Press, 2002.

SILVA, Virgílio Afonso da. O proporcional e o razoável. Revista dos Tribunais, São Paulo, ano 91, n. 798, abr. 2002.

A constitucionalização do direito: os direitos fundamentais nas relações entre particulares. São Paulo: Malheiros, 2008.

Direitos fundamentais: conteúdo essencial, restrições, eficácia. 2. ed. São Paulo: Malheiros, 2010.

Ponderação e objetividade na interpretação constitucional. In: MACEDO JUNIOR, Ronaldo Porto; BARBIERI, Catarina Helena Cortada (Org.). Direito e interpretação: racionalidades e instituições. São Paulo: Direito GV/Saraiva, 2011.

SILVA, Virgílio Afonso da; MENDES, Conrado Hübner. Habermas e a jurisdição constitucional. In: NOBRE, Marcos; TERRA, Ricardo (Org.). Direito e democracia: um guia de leitura de Habermas. São Paulo: Malheiros, 2008. p. 199-222.

STRECK, Lenio Luiz. Verdade e consenso. 3. ed. Rio de Janeiro: Lumen Juris, 2009.

URBAN, Renan Lucas Dutra. Colisões entre regras e princípios, otimização e derrotabilidade: o caráter definitivo das regras. 2017. 100 f. Dissertação (Mestrado em Direito) - Faculdade de Ciências Humanas e Sociais, Universidade Estadual Paulista "Júlio de Mesquita Filho", Franca, 2017.

RECEBIDO: $16 / 11 / 2018$

APROVADO: $31 / 03 / 2019$ 